\title{
Seasonal Predictability of Summer Rainfall over South America
}

\author{
RODRIGO J. BOMBARDI \\ Department of Geography, Texas A\&M University, College Station, Texas, and Department of Atmospheric, \\ Oceanic, and Earth Sciences, George Mason University, Fairfax, Virginia \\ Laurie Trenary, Kathy Pegion, Benjamin Cash, Timothy DelSole, \\ AND JAMES L. KINTER III \\ Department of Atmospheric, Oceanic, and Earth Sciences, George Mason University, Fairfax, Virginia
}

(Manuscript received 29 March 2018, in final form 25 June 2018)

\begin{abstract}
The seasonal predictability of austral summer rainfall is evaluated in a set of retrospective forecasts (hindcasts) performed as part of the Minerva and Metis projects. Both projects use the European Centre for Medium-Range Weather Forecasts (ECMWF) Integrated Forecast System (IFS) coupled to the Nucleus for European Modelling of the Ocean (NEMO). The Minerva runs consist of three sets of hindcasts where the spatial resolution of the model's atmospheric component is progressively increased while keeping the spatial resolution of its oceanic component constant. In the Metis runs, the spatial resolution of both the atmospheric and oceanic components are progressively increased. We find that raw model predictions show seasonal forecast skill for rainfall over northern and southeastern South America. However, predictability is difficult to detect on a local basis, but it can be detected on a large-scale pattern basis. In addition, increasing horizontal resolution does not lead to improvements in the forecast skill of rainfall over South America. A predictable component analysis shows that only the first predictable component of austral summer precipitation has forecast skill, and the source of forecast skill is El Niño-Southern Oscillation. Seasonal prediction of precipitation remains a challenge for state-of-the-art climate models. Positive benefits of increasing model resolution might be more evident in other atmospheric fields (i.e., temperature or geopotential height) and/or temporal scales (i.e., subseasonal temporal scales).
\end{abstract}

\section{Introduction}

North and central South America receive more than $50 \%$ of their annual precipitation during the austral summer months [December-February (DJF)]. The heavy precipitation is associated with the peak phase of the South American monsoon system. During this period, the most intense convective activity over land is centered over the southern Amazon and central-western Brazil, the core region of the monsoon (Zhou and Lau 1998; Vera et al. 2006; Marengo et al. 2012; Carvalho and Cavalcanti 2016). An important feature of the South American monsoon is the presence of the South Atlantic convergence zone (SACZ), a northwestsoutheast-oriented band of cloudiness and heavy precipitation that extends from the core monsoon region

\footnotetext{
Corresponding author: Rodrigo J. Bombardi, rjbombardi@tamu. edu
}

to the subtropical South Atlantic (e.g., Carvalho et al. 2002, 2004). Despite the continuous development and improvement of climate models, the deterministic seasonal prediction of precipitation over the core monsoon region remains a challenge (Becker et al. 2014; Jia et al. 2015; Osman and Vera 2017).

Early attempts to evaluate the predictability of precipitation over South America relied on simulations with coarse-resolution global atmospheric models using prescribed observed sea surface temperature (SST; e.g., Barreiro et al. 2002, 2005; Misra 2004; Taschetto and Wainer 2008). Commonly known as Atmospheric Model Intercomparison Project (AMIP)-style runs (e.g., Gates et al. 1999), these experiments consisted of relatively long integrations ( $\sim 30$ years) and relatively few ensemble members (five members). They found that summer precipitation over equatorial South America is predictable, while poor forecast skill is found over subtropical and extratropical regions. The high predictability of 
TABLE 1. Experiment descriptions.

\begin{tabular}{lccc}
\hline & & & Spatial resolution \\
\cline { 3 - 3 } \multicolumn{1}{c}{ Expt } & Period & Atmosphere component & Ocean component \\
\hline Minerva T319 & $1980-2020$ & $\sim 64 \mathrm{~km}$ & $1^{\circ}\left(\right.$ refined to $1 / 3^{\circ}$ near the equator) \\
Minerva T639 & $1980-2010$ & $\sim 32 \mathrm{~km}$ & $1^{\circ}\left(\right.$ refined to $1 / 3^{\circ}$ near the equator) \\
Minerva T1279 & $1980-2010$ & $\sim 16 \mathrm{~km}$ & $1^{\circ}$ (refined to $1 / 3^{\circ}$ near the equator) \\
Metis Tco199 & $1986-2015$ & $\sim 54 \mathrm{~km}$ & $1^{\circ}$ (refined to $1 / 3^{\circ}$ near the equator) \\
Metis Tco639 & $1986-2015$ & $\sim 16 \mathrm{~km}$ & $0.25^{\circ}$ global (no refinement) \\
\hline
\end{tabular}

precipitation over the equator is because the intertropical convergence zone (ITCZ) is dominated by sea surface temperature forcing (Taschetto and Wainer 2008). The SACZ, however, is less predictable than the ITCZ. In addition, the oceanic portion of the SACZ is more predictable than its continental portion, which is dominated by internal variability (Barreiro et al. 2002, 2005; Taschetto and Wainer 2008). Hirata and Grimm (2018) showed that precipitation associated with the SACZ is predictable within a 2-week lead time when the simulations are calibrated. However, the seasonal prediction of the SACZ remains a challenge.

More recently, seasonal predictability studies have moved away from AMIP-type of runs and focused on dynamical seasonal prediction (Shukla et al. 2000), which were shown to yield better results (Misra 2004). Even using state-of-the-art global coupled climate models, skillful seasonal predictability of the South American summer rainfall is largely confined to equatorial regions of South America (Becker et al. 2014; Jia et al. 2015; Osman and Vera 2017). Recent work also documents moderate skill over southeast South America (Becker et al. 2014; Jia et al. 2015; Osman and Vera 2017) and the extratropical Andes (Osman and Vera 2017).

Jia et al. (2015) found that increased atmospheric and land resolution combined with statistical optimization analysis (predictable component analysis) results in improved seasonal forecasts of 2 -m temperature and precipitation. In this work, we build on their findings by evaluating the predictability of summer precipitation over South America using a set of high-resolution retrospective forecasts. These reforecasts have a range of spatial resolutions for the model's atmospheric component alone as well as a range of spatial resolutions of both the atmospheric and oceanic components. The original aspects of this work include the evaluation of the incremental increase in resolution of both atmospheric and oceanic model components as well as the predictable component analysis of summer precipitation focusing on South America.

Section 2 describes the data, model, and the simulations. The model representation of DJF precipitation is presented in section 3 . Section 4 presents a predictability analysis for the different model simulations. The predictability of large-scale patterns of precipitation over South America is explored in section 5. Section 6 presents the conclusions.

\section{Data, model, and experiments}

We evaluate the seasonal predictability of the austral summer (DJF) rainfall over South America using retrospective forecasts (hindcasts) performed as part of the Minerva (Cash et al. 2017) and Metis (in progress) projects. The hindcasts were carried out using the European Centre for Medium-Range Weather Forecasts (ECMWF) Integrated Forecast System (IFS) coupled to the Nucleus for European Modelling of the Ocean (NEMO) (Molteni et al. 2011). Hereafter we will refer to the coupled system as IFS_NEMO.

Minerva runs were performed using a linear grid while Metis runs were carried out using a cubic-octahedral grid (Dando 2015). Hindcasts in the Minerva project were performed for three different atmospheric resolutions (T319, T639, and T1279, with equivalent grid spacing of 64,32 , and $16 \mathrm{~km}$, respectively), each coupled to the same $1^{\circ}$ ocean resolution refined to $1 / 3^{\circ}$ near the equator. Integrations in the Metis project were carried out for three different atmospheric resolutions (Tco199, Tco639, and Tco1279, with equivalent grid spacing of 54, 16 , and $9 \mathrm{~km}$, respectively), each coupled to an ocean model with different resolutions $\left(1^{\circ}, 0.25^{\circ}\right.$, and $0.25^{\circ}$, respectively) also refined near the equator (see Table 1 ). In this work, we analyze a subset of the hindcasts performed under projects Minerva and Metis. For consistency, we selected only hindcasts starting on 1 November that consist of 7-month-long integrations, with 15 ensemble members for each year in a 30 -yr period. Therefore, all results presented in this study refer to DJF averages, which start at a 1-month lead time from model initialization. Table 1 summarizes the hindcasts used in this study. Hindcasts were validated against precipitation data from the Climate Prediction Center Unified Precipitation (CPC_UNI; Chen et al. 2008; Xie et al. 2007), with $0.5^{\circ}$ resolution. In cases where comparisons require 
a) Minerva T319

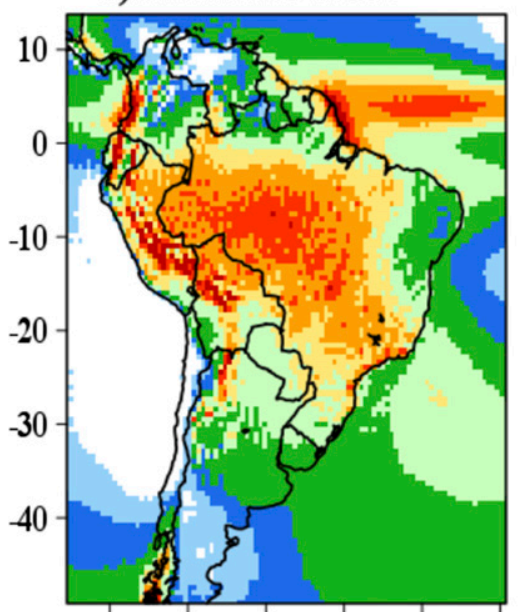

d) Metis Tco199

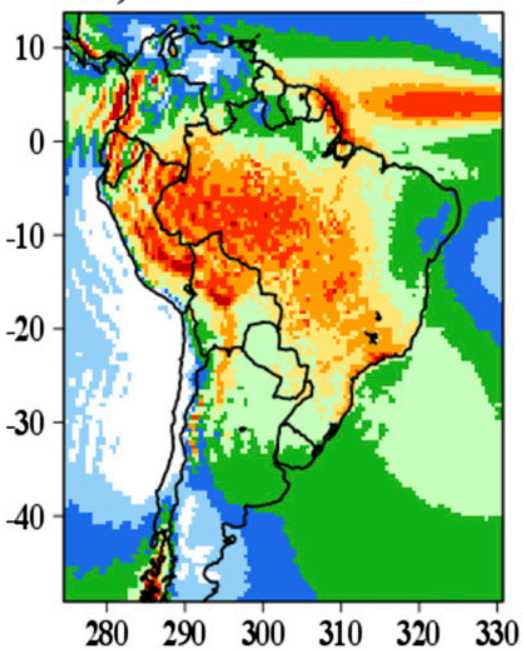

b) Minerva T639

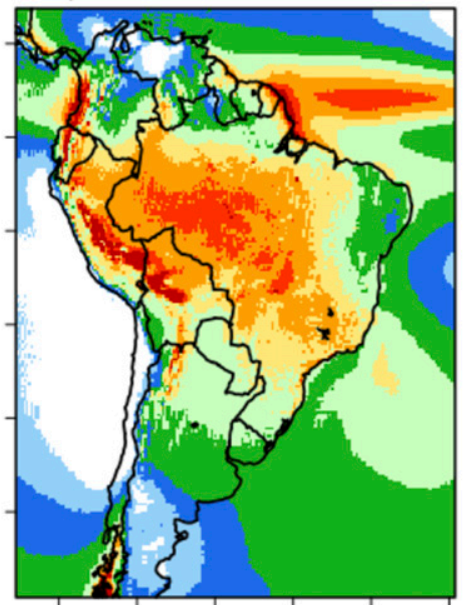

e) Metis Tco639

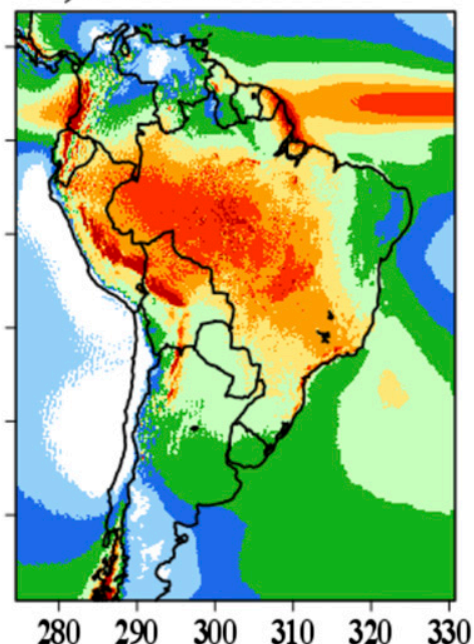

c) Minerva T1279

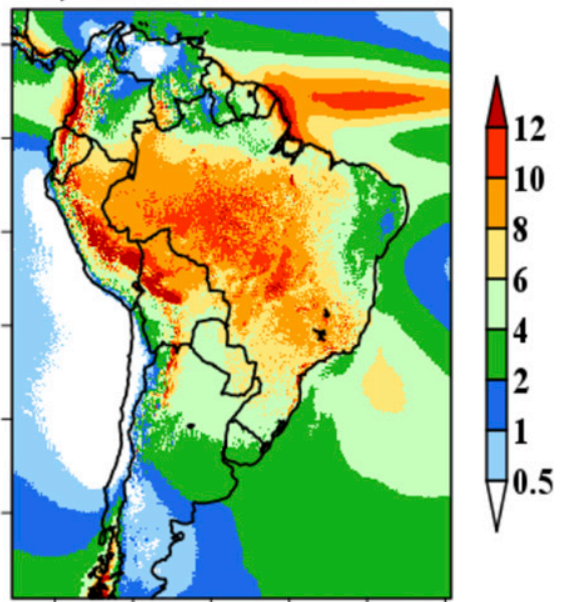

f) Obs. CPC

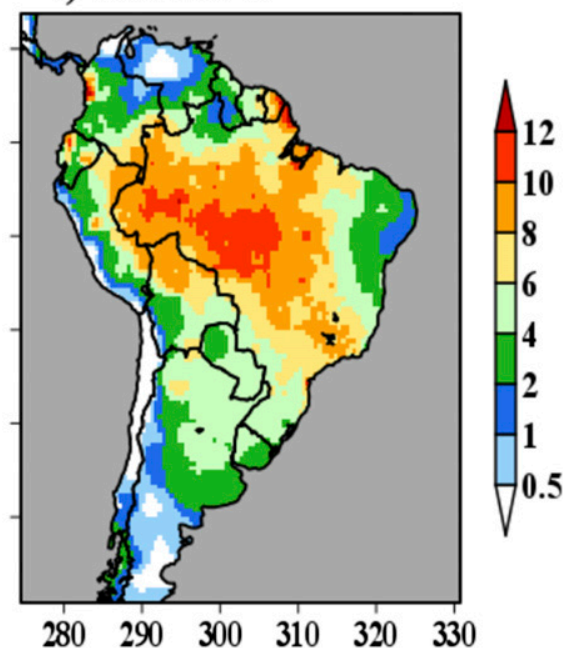

FIG. 1. Mean DJF precipitation for (a) Minerva T319, (b) Minerva T639, (c) Minerva T1279, (d) Metis Tco199, (e) Metis Tco639, and (f) CPC_UNI. Values calculated for the approximate whole period of available simulations (Minerva 1980-2010; Metis 1986-2015; CPC UNI 1980-2015).

matching grids, we first calculated DJF means for each year and then we regridded the datasets into the coarser grid (Minerva T319) using a linear interpolation. This same process was applied to observations given that the Minerva T319 grid is coarser than the grids of observed precipitation.

\section{IFS_NEMO representation of DJF precipitation}

Figures 1 and 2 show the mean and the interannual standard deviation of seasonal means of summer (DJF) precipitation simulated by the Minerva (1980-2010) and Metis (1986-2015) hindcasts, as well as the observed values from CPC_UNI (1980-2015). Although there are differences among experiments, all Minerva and Metis runs reproduce the CPC_UNI mean spatial patterns of
DJF precipitation, including low precipitation values over northeast Brazil and the maximum precipitation over the Amazon and central Brazil (Fig. 1). The model is less accurate in representing the spatial pattern of the interannual standard deviation of DJF precipitation, as it underestimates the variability of summer precipitation over the Amazon basin (Fig. 2).

The model shows strong negative biases over Peru and along the Andes (Fig. 3), likely due to the effects of topography in the model allied to sampling issues in the observations. Positive biases are found over the mouth of the Amazon River in all experiments. Metis experiments show negative biases over the western Amazon (Figs. 3d,e). To some degree all models show negative precipitation biases over Paraguay and central-western Brazil (Fig. 3). 
a) Minerva T319

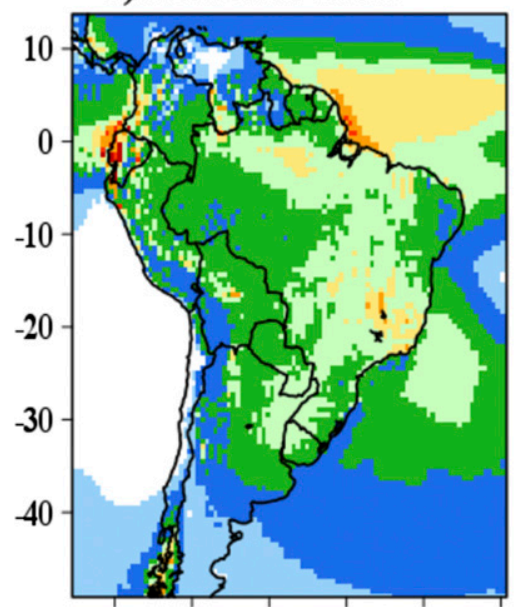

d) Metis Tco199

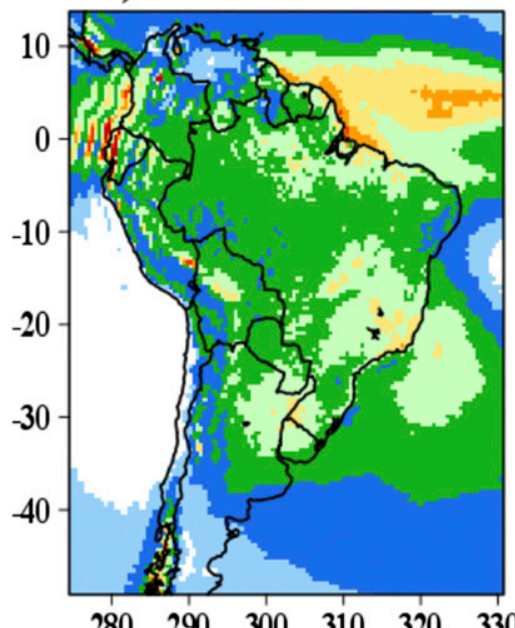

b) Minerva $\mathrm{T} 639$

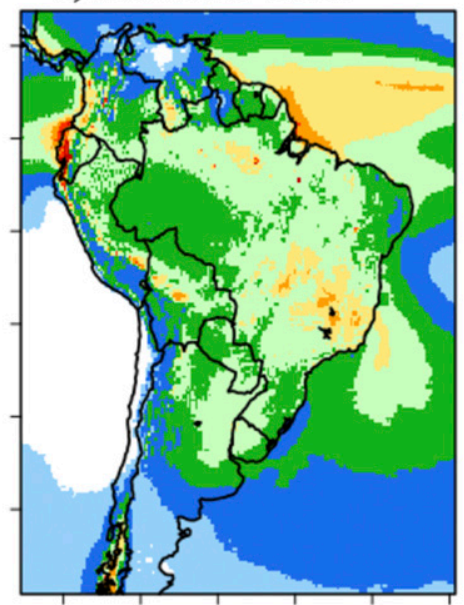

e) Metis Tco639

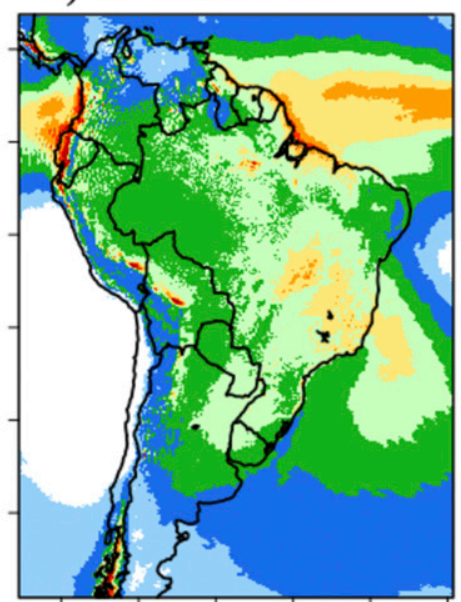

$\begin{array}{llllll}280 & 290 & 300 & 310 & 320 & 330\end{array}$ c) Minerva T1279

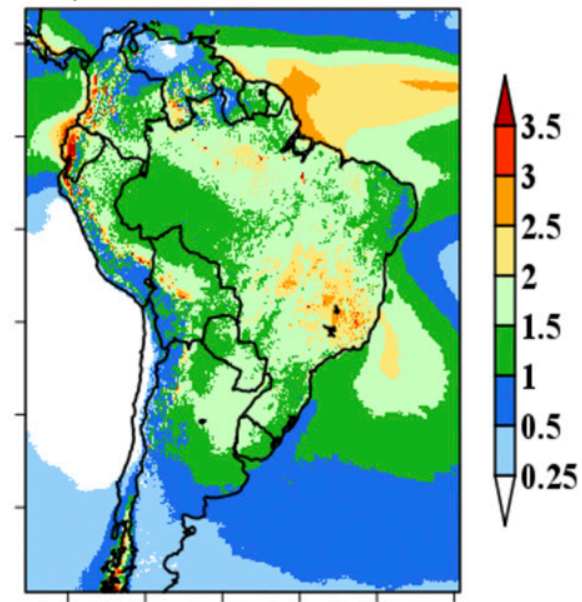

f) Obs. CPC

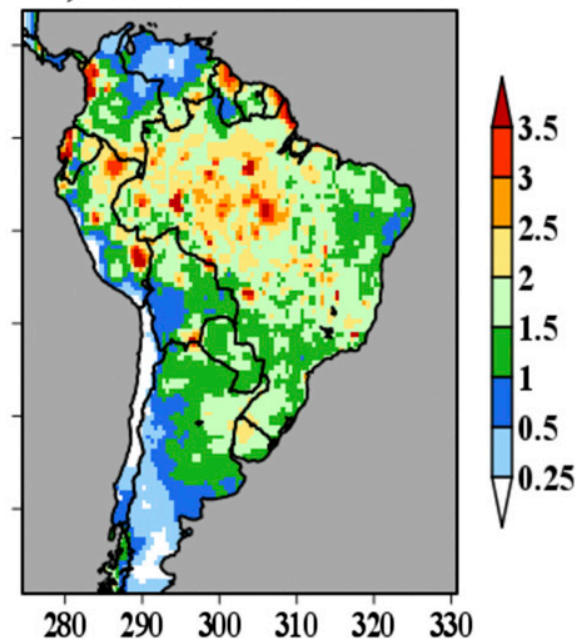

FIG. 2. Interannual standard deviation of DJF precipitation for (a) Minerva T319, (b) Minerva T639, (c) Minerva T1279, (d) Metis Tco199, (e) Metis Tco639, and (f) CPC_UNI. Values calculated for the whole period of available simulations (Minerva 1980-2010; Metis 1986-2015; CPC_UNI 1980-2015).

\section{Predictability of DJF precipitation over South America}

Skillful prediction of monsoonal precipitation is a challenge for current global climate models (e.g., Becker et al. 2014) because the dynamics necessarily involve the interaction of multiple scales of motion and different underlying dynamics (Vera et al. 2006; Marengo et al. 2012). A simple metric to evaluate prediction skill is the anomaly correlation coefficient at each grid point independently. Figure 4 shows the anomaly correlation between DJF precipitation anomalies from CPC_UNI and the reforecasts from the Minerva and Metis projects. The anomaly correlation was calculated using the ensemble mean of each year of simulation of each experiment. We chose to use CPC_UNI to validate the reforecasts because this dataset comprises the whole period of simulations. The IFS_NEMO has statistically significant anomaly correlations over part of the La Plata basin and northern South America, including part of northeastern Brazil. No significant correlations are present over central South America, the core of the South American monsoon. Figure $4 \mathrm{f}$ shows the contours of the areas with statistically significant anomaly correlations for experiments Minerva T319 and T639 and Metis Tco199. Apart from small localized differences, the regions that show statistically significant anomaly correlation (or forecast skill) are very similar across experiments.

We have established that the IFS_NEMO has skill in predicting DJF precipitation over northern South America and that increasing spatial resolution had no 
a) Minerva T319

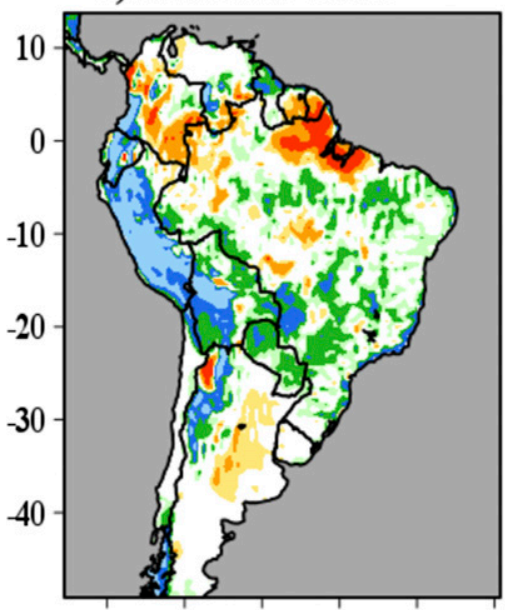

d) Metis T199

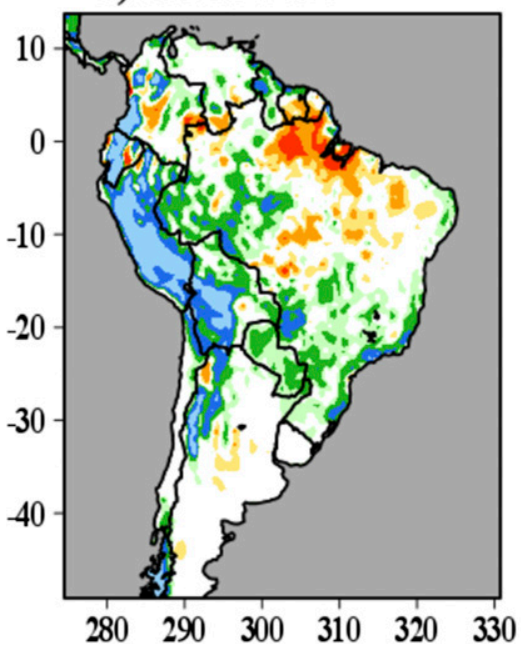

b) Minerva T 639

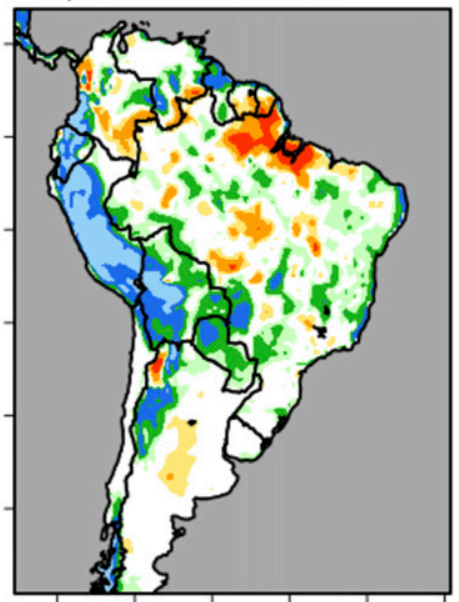

e) Metis T639

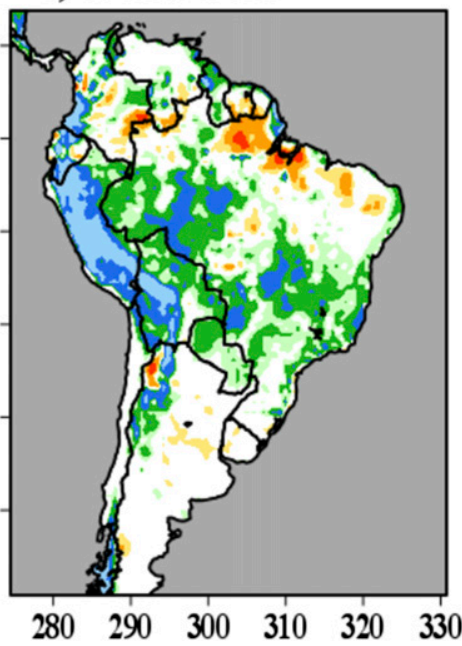

c) Minerva $T 1279$

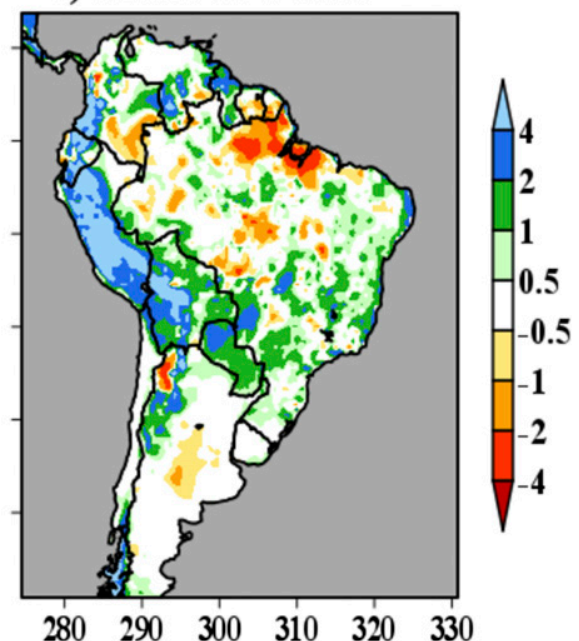

FIG. 3. DJF precipitation bias (with respect to CPC_UNI) for (a) Minerva T319, (b) Minerva T639, (c) Minerva T1279,(d) Metis Tco199, and (e) Metis Tco639. Only periods when simulations and observations coincide were used. clear impact in forecast skill (Fig. 4). We now investigate if the increase in resolution leads to increased predictability in the model. Therefore, we performed a signal-to-noise analysis of the Minerva and Metis simulations. The unbiased signal variance, $\sigma_{S}^{2}$, and noise variance, $\sigma_{N}^{2}$, are calculated according to Eqs. (1) and (2), respectively:

$$
\begin{aligned}
\sigma_{S}^{2} & =\frac{1}{N-1} \sum_{i}^{N}\left[\left(\bar{X}_{i}\right)^{2}\right], \\
\sigma_{N}^{2} & =\frac{1}{N}\left(\sum_{i}^{N}\left\{\frac{1}{M-1} \sum_{j}^{M}\left[\left(X_{i j}^{\prime}\right)^{2}\right]\right\}\right),
\end{aligned}
$$

where $N$ is the number of years, $M$ is the number of ensemble members per year, and $\bar{X}_{i}$ is the ensemble mean of precipitation anomalies for year $i$. The anomalies were calculated (at each grid point) by removing the mean (Fig. 1) from each ensemble member of each year. $X_{i j}^{\prime}=X_{i j}-\bar{X}_{i}$, where $X_{i j}$ represents the precipitation anomalies for each year $i$ and each ensemble member $j$. The signal variance is determined based on the interannual variance of the ensemble mean and represents the predictable signal, while the noise variance is determined based on the variability of individual ensemble members about the ensemble mean and represents the unpredictable noise. The ratio between signal and noise variances is a measure of predictability. Where the signal is larger than the noise, there is predictability. Conversely, no predictability exists where the signal is smaller than the noise. In a perfect model, this ratio is related to the expected anomaly correlation skill as a function of the number of ensemble members (e.g., Sardeshmukh et al. 2000; Kumar and Hoerling 2000; Compo and Sardeshmukh 2004). This relationship allows us to diagnose the skill of precipitation in terms of 
a) Minerva $\mathbf{T 3 1 9}$

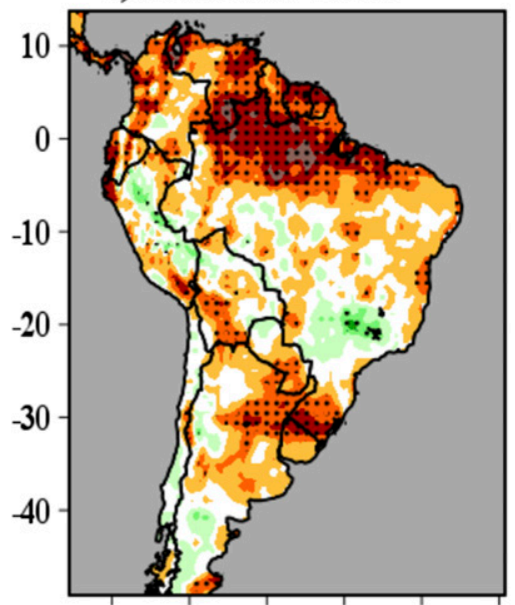

d) Metis Tco199

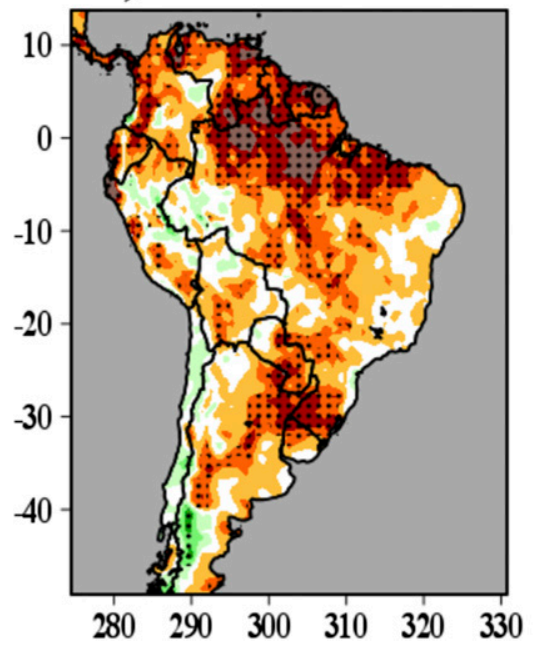

b) Minerva T639

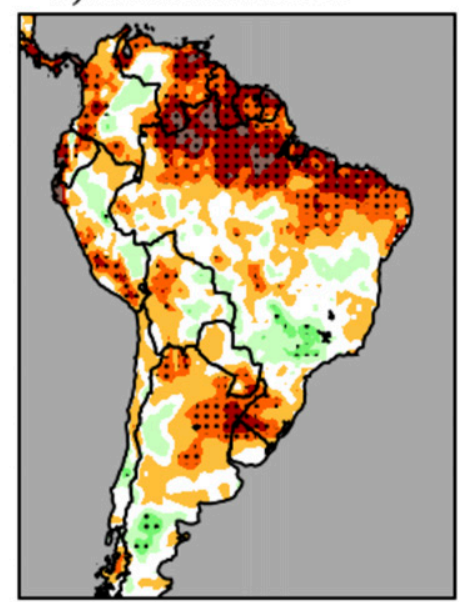

e) Metis Tco639

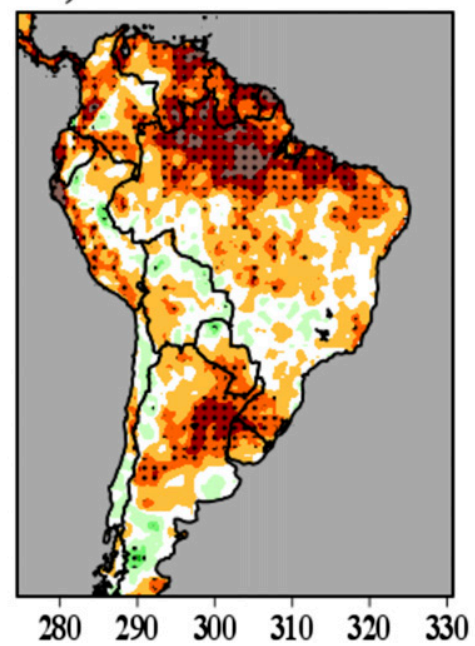

c) Minerva T1279

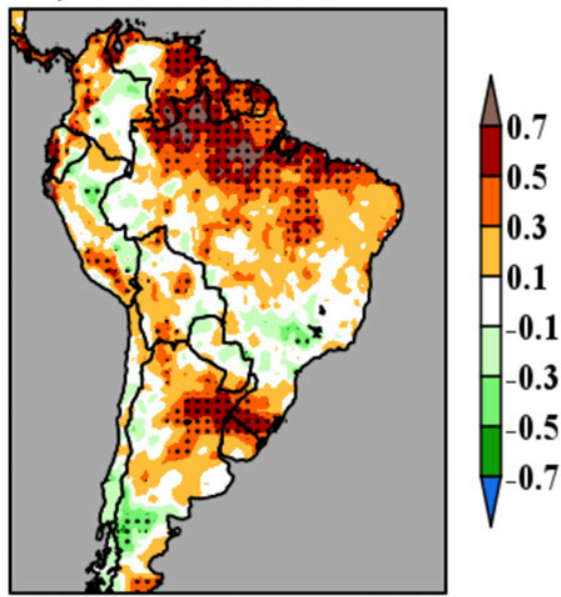

f) Significant Areas
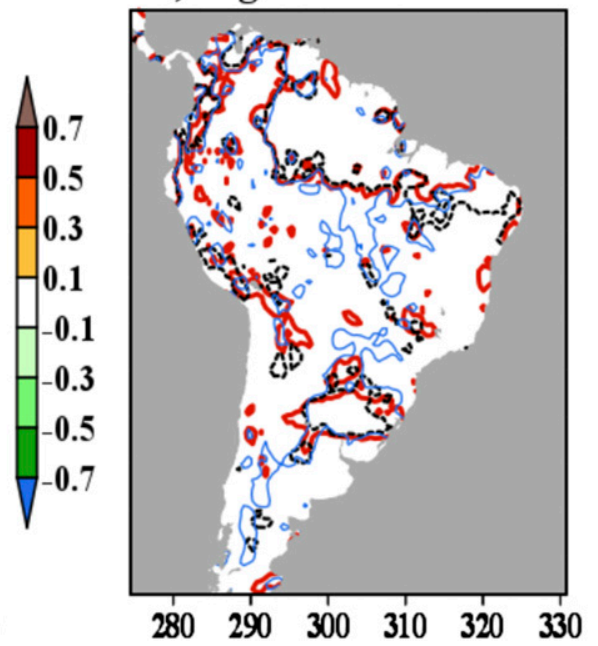

FIG. 4. DJF precipitation anomaly correlation (against CPC_UNI) for (a) Minerva T319, (b) Minerva T639, (c) Minerva T1279, (d) Metis Tco199, and (e) Metis Tco639. Only periods when simulations and observations coincide were used. Prior to the calculation of correlations, we first calculated DJF means for each year of each dataset and then we regridded the datasets into the coarser grid (Minerva T319) using a linear interpolation. The stippling shows regions that are statistically significant at the $5 \%$ level according to a $t$ test. (f) Areas with statistically significant anomaly correlation values for Minerva T319 (thick red line), Minerva T639 (dashed black line), and Metis Tco199 (thick blue line).

the predictable signal and unpredictable noise and to understand how changes in resolution impact these components of the predictability.

The signal variance (Fig. 5) is highest over parts of northern South America and over the equatorial Atlantic Ocean, consistent with the region of highest skill (Fig. 4). A secondary signal maximum is present over the La Plata basin region (Fig. 5). In the Metis experiment (Figs. 5d,e), there is a slight decrease in signal variance as the spatial resolution of the experiments increases (Fig. 5f). This effect is very evident over equatorial regions, the Andes, southeast South America, and the subtropical South Atlantic Ocean. This indicates that increasing resolution does not improve the predictable signal in these experiments, consistent with the lack of improved skill based on resolution.

The noise variance is largest over central and southeastern Brazil, the equatorial Atlantic Ocean, and the La Plata basin region (Fig. 6). No significant differences in noise variance are found among the Minerva experiments (Figs. 6a-c). However, the Metis experiments (Figs. 6d,e) show a decrease in noise variance over the equatorial oceans and northeast Brazil as the spatial resolution increases (Fig. 6f). The main source of noise over central and southeast Brazil is probably associated with the South Atlantic convergence zone, which is 
a) Minerva $\mathrm{T319}$

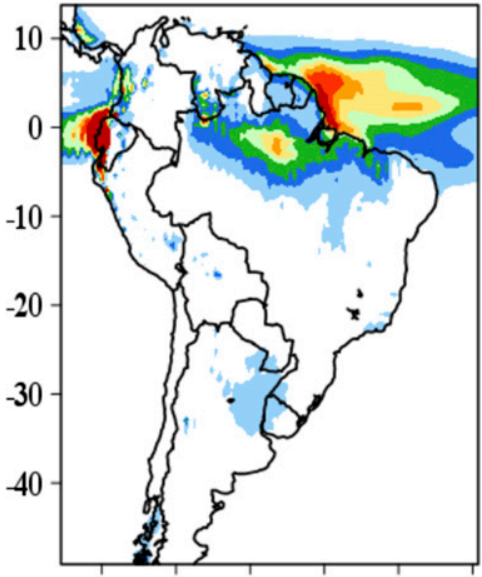

d) Metis Tco199

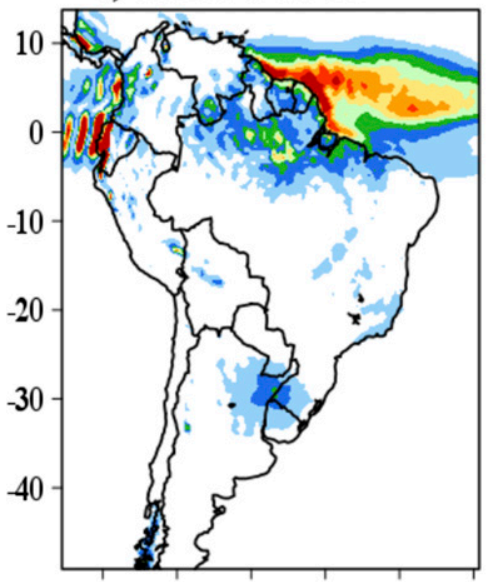

$\begin{array}{llllll}280 & 290 & 300 & 310 & 320 & 330\end{array}$

\section{b) Minerva T639}

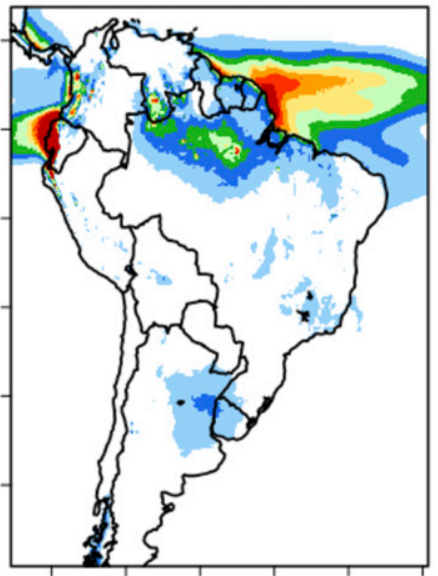

e) Metis T co639

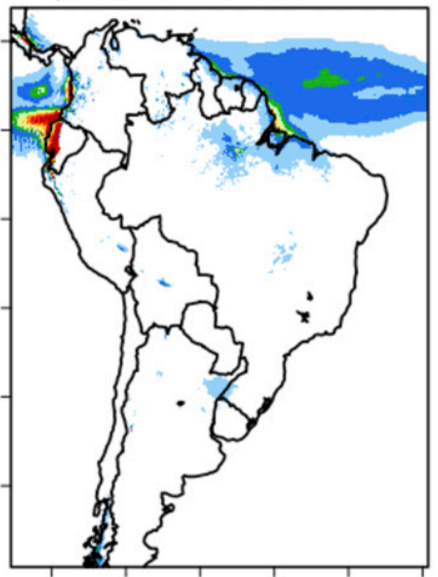

$\begin{array}{llllll}280 & 290 & 300 & 310 & 320 & 330\end{array}$ c) Minerva $\mathbf{T} 1279$

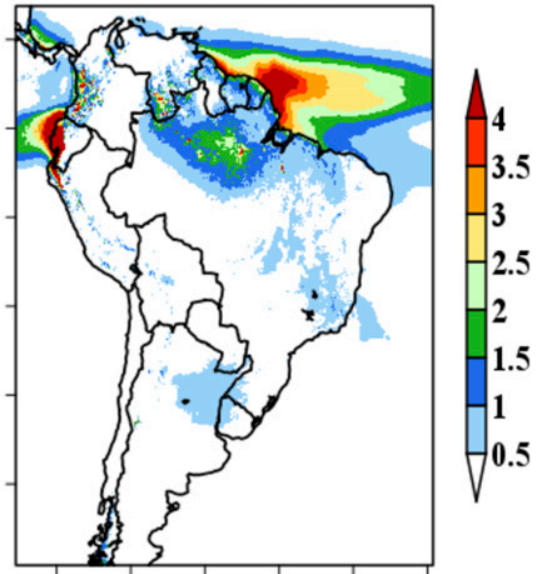

f) Metis Tco199/Tco639

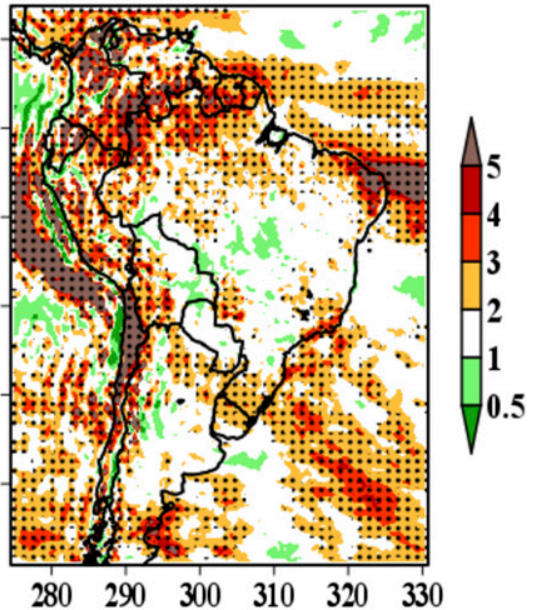

FIG. 5. Forecast signal variance for DJF precipitation for (a) Minerva T319, (b) Minerva T639, (c) Minerva T1279, (d) Metis Tco199, and (e) Metis Tco639. The signal was calculated for the whole period of available data (Minerva 1980-2010; Metis 1986-2015). (f) The ratio between Metis Tco199 and Metis Tco639. The results in (a)-(e) were calculated on the native grid, while the results in (f) were calculated regridding datasets to a coarser grid. The stippling shows regions that are statistically significant at the $5 \%$ level according to an $F$ test.

strongly influenced by intraseasonal variability (Jones and Carvalho 2002; Muza et al. 2009; Gonzalez and Vera 2014; Vera et al. 2018).

The signal-to-noise analysis shows predictability of DJF precipitation only over the equatorial Pacific Ocean (Fig. 7). Therefore, we found that the model has skill (Fig. 4) but lacks predictability (Fig. 7). These two seemingly contradictory statements could be explained by the fact that a large-scale pattern in the model might be predictable but this predictability might not be detectable by a univariate analysis if the variability at the individual grid cells is dominated by noise. Interestingly, the predictability of DJF precipitation in the Metis experiment decreases over northern South America with increasing resolution (Fig. 7f). The lack of predictability over the domain of the South American monsoon is probably because monsoons are affected by a range of phenomena with different time scales. Moreover, local processes play a large role in monsoon variability (e.g., Vera et al. 2006; Marengo et al. 2012). Such processes present a challenge for seasonal forecasts and, therefore, the increase in spatial resolution results in a decrease of signal variance.

\section{Predictability of large-scale summer precipitation patterns over South America}

\section{a. Eigenvectors of the Laplace operator}

While the local significance test found no evidence of predictability in the model (Fig. 7), it is possible that there are large-scale patterns that contribute to the skill 
a) Minerva $\mathrm{T} 319$

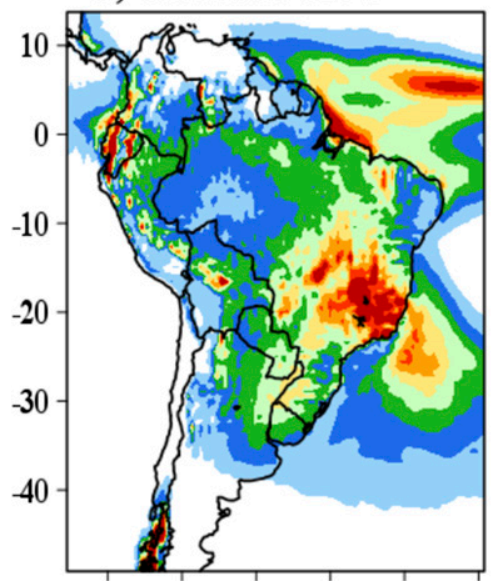

d) Metis Tco199

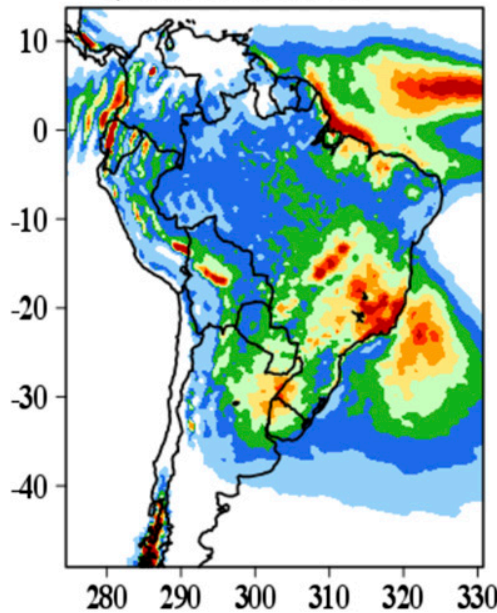

b) Minerva T639

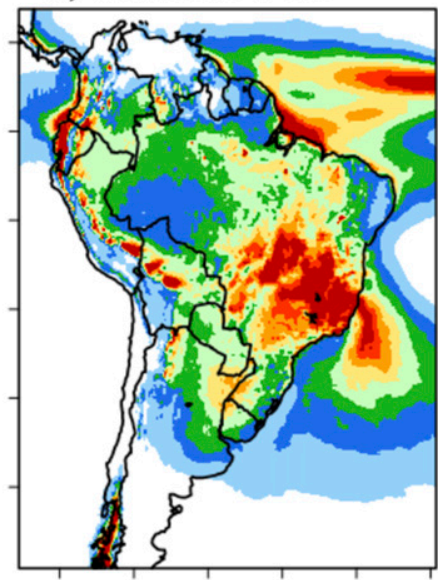

e) Metis $T$ co639

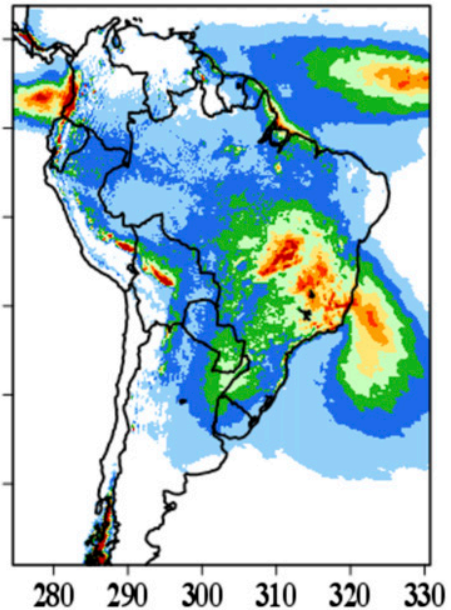

c) Minerva $\mathbf{T} 1279$

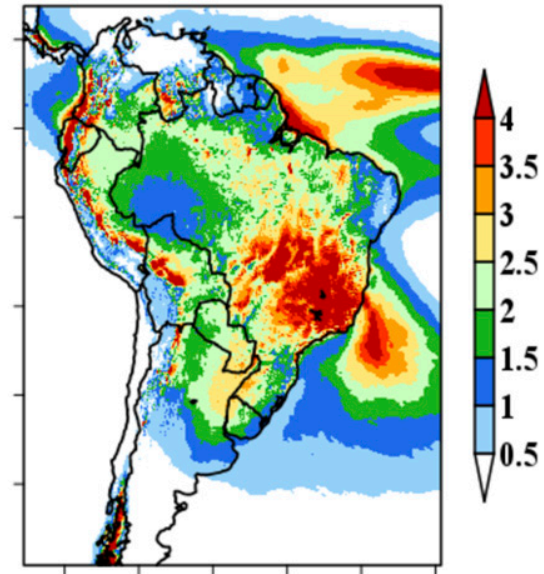

f) Metis T co199/T co639

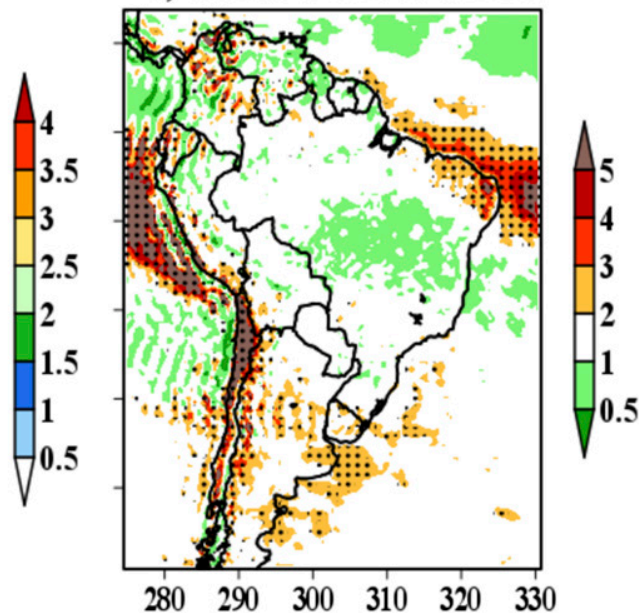

FIG. 6. Forecast noise variance for DJF precipitation for (a) Minerva T319, (b) Minerva T639, (c) Minerva T1279, (d) Metis Tco199, and (e) Metis Tco639. The noise was calculated for the whole period of available data (Minerva 1980-2010; Metis 1986-2015). (f) The ratio between Metis Tco199 and Metis Tco639. The results in (a)-(e) were calculated on the native grid, while the results in (f) were calculated regridding datasets to a coarser grid. The stippling shows regions that are statistically significant at the $5 \%$ level according to an $F$ test.

of the model. To isolate these large-scale patterns, the anomalous precipitation fields are projected onto the Laplacian operator (DelSole and Tippett 2015) over South America. As noted by DelSole et al. (2017), Laplacian eigenvectors provide a convenient orthogonal basis set that is ordered by length scale. For instance, Fourier series used to decompose time series are a special case of Laplacian eigenvectors. In this work, we use eigenvectors of the Laplace operator to identify spatial patterns that are orthogonal with respect to an area-weighted inner product. Analogously to time series decomposition, these spatial patterns represent the decomposition of the domain by length scale. The eigenvectors of the Laplace operator over South America were obtained using a Green's function method (DelSole and Tippett 2015).
The Laplacian eigenvectors provide a set of orthogonal large-scale patterns (Fig. 8) that are domain dependent but data independent, which makes them suitable for comparing different simulations over the same domain. The first eigenvector is not shown because it equals a spatially uniform pattern over the domain (i.e., the largest spatial scale that fits in the domain). The second and third eigenvectors measure the east-west and north-south gradients, respectively. The next two eigenvectors correspond to a tripole and quadrupole, etc., of decreasing length scale.

\section{b. Predictable component analysis}

We projected the DJF precipitation anomaly fields onto the eigenvectors of the Laplacian operator over South America. Then, we applied a predictable component 
a) Minerva $\mathrm{T} 319$

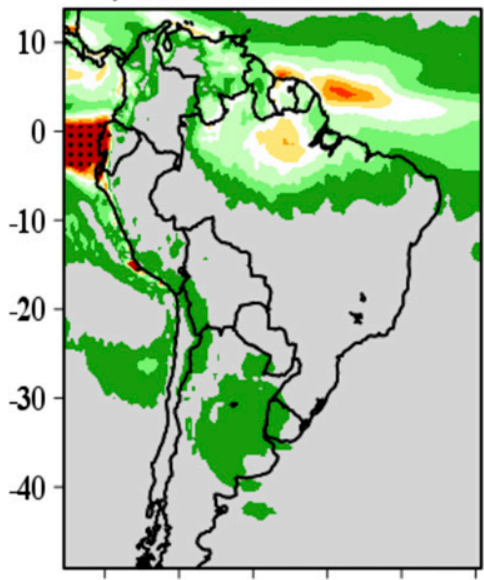

d) Metis Tco199

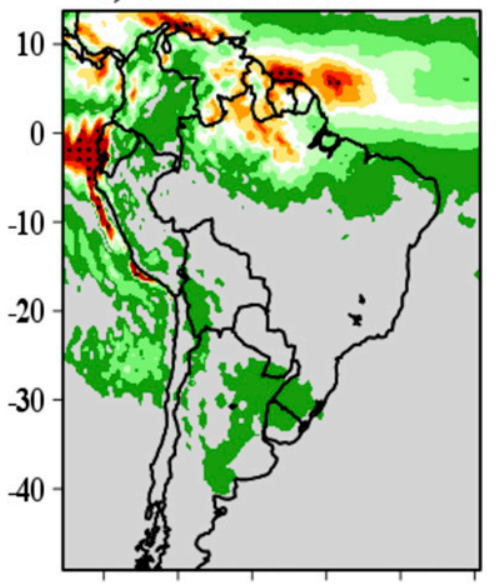

$\begin{array}{llllll}280 & 290 & 300 & 310 & 320 & 330\end{array}$

\section{b) Minerva T639}

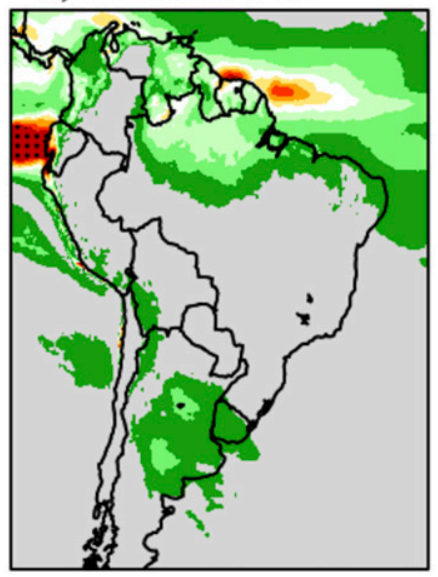

e) Metis Tco639

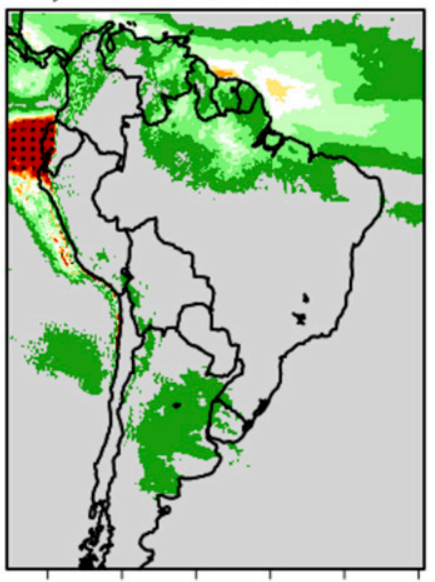

$\begin{array}{llllll}280 & 290 & 300 & 310 & 320 & 330\end{array}$ c) Minerva T1279

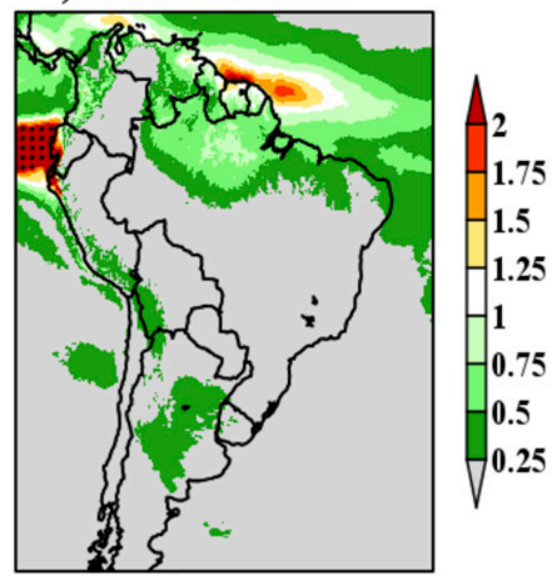

f) Metis Tco199/Tco639

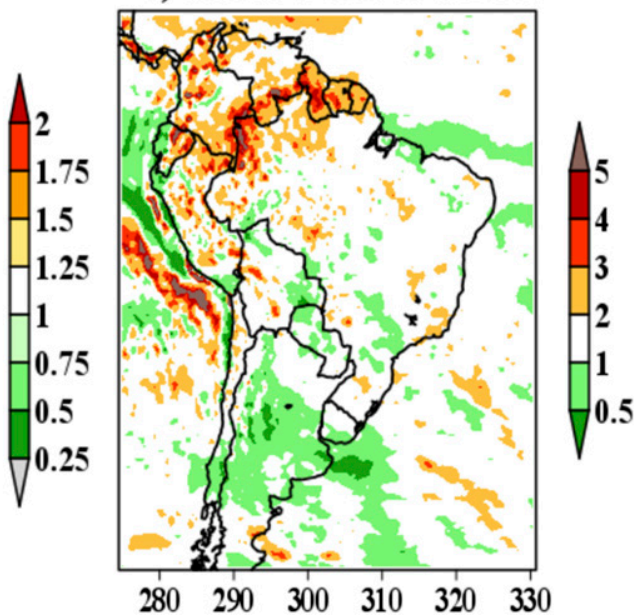

FIG. 7. Signal-to-noise ratio of DJF precipitation for (a) Minerva T319, (b) Minerva T639, (c) Minerva T1279, (d) Metis Tco199, and (e) Metis Tco639. The signal-to-noise ratio was calculated for the whole period of available data (Minerva 1980-2010; Metis 1986-2015). (f) The ratio between Metis Tco199 and Metis Tco639. The results in (a)-(e) were calculated on the native grid, while the results in (f) were calculated regridding datasets to a coarser grid. The stippling shows regions that are statistically significant at the $5 \%$ level according to an $F$ test. No test was applied to (f) because the $F$ test does not test the significance of a ratio of ratios.

analysis (PrCA; DelSole and Tippett 2008) to the fields of projected precipitation anomalies following the methodology used in DelSole et al. (2017). Similar to an empirical orthogonal function (EOF) analysis, the PrCA method is based on solving an eigenvalue problem. However, instead of maximizing the variance, like an EOF, the PrCA maximizes the signal-to-noise ratio [the ratio between Eqs. (1) and (2)]. In other words, the PrCA finds the combination of patterns that maximizes the hindcast signal-to-noise ratio. For example, when the eigenvalues (and corresponding eigenvectors) are ordered in descending order, the first eigenvector maximizes the signal-to-noise ratio. The second eigenvector maximizes the signal-to-noise ratio subject to being uncorrelated with the first eigenvector, and so on. These solutions define the predictable components, the first of which will be called the "most predictable component."

Figure 9a shows the relationship between the maximized signal-to-noise ratio of the main predictable component (resulting from the PrCA) and the number of Laplacian eigenvectors considered in the PrCA calculation. The maximized signal-to-noise ratio increases as the number of Laplacian eigenvectors increases, but eventually plateaus. With the exception of Metis Tco639, little increase in signal-to-noise ratio is observed after the tenth Laplacian eigenvector is introduced. Moreover, considering more than 10 Laplacian eigenvectors did not change our results significantly (not shown). Therefore, we choose to fix the number of Laplacian eigenvectors 
a) Laplacian 2

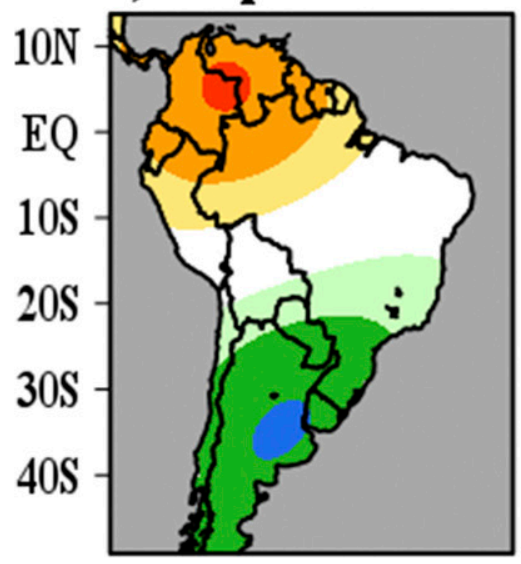

d) Laplacian 5

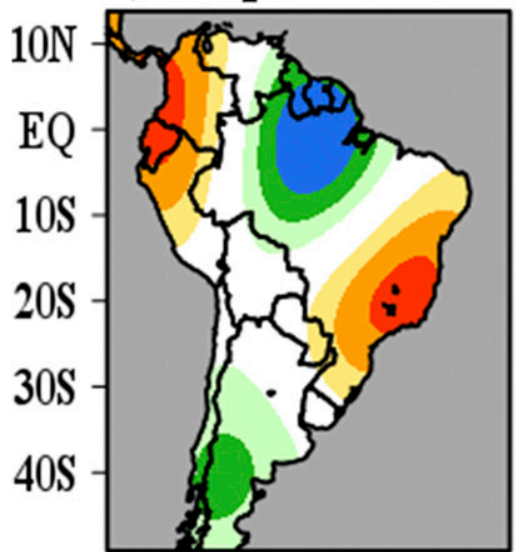

g) Laplacian 8

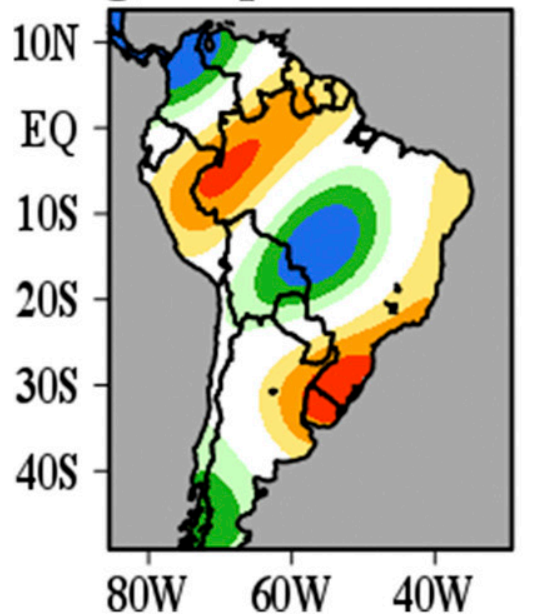

b) Laplacian 3

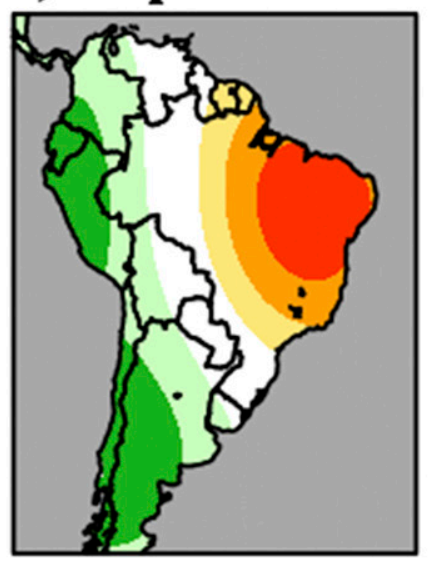

e) Laplacian 6

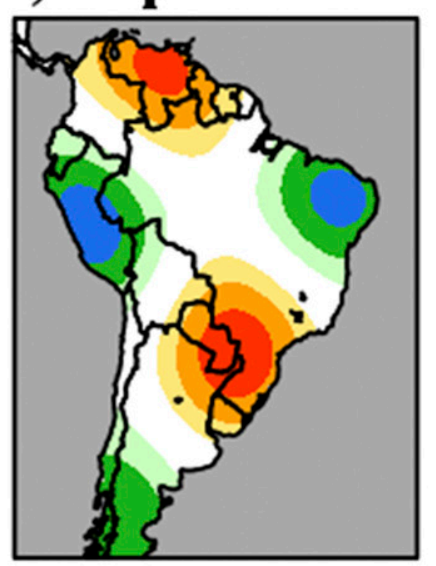

h) Laplacian 9

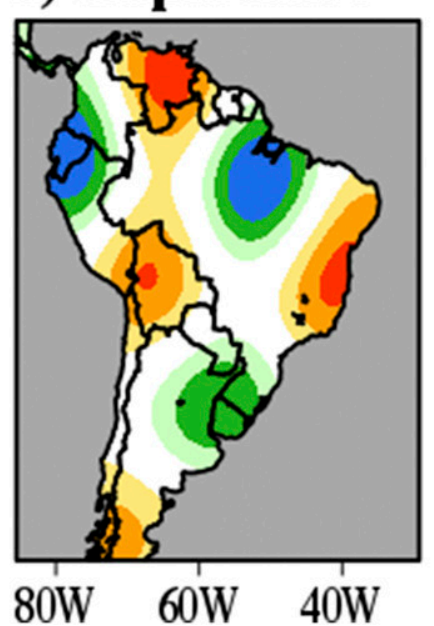

c) Laplacian 4

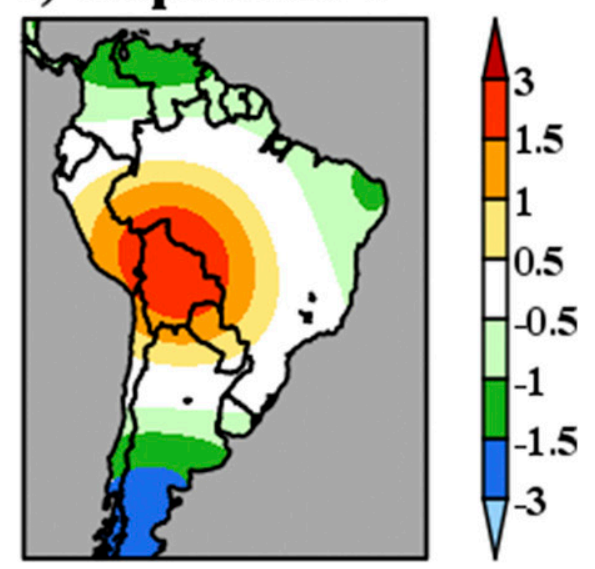

f) Laplacian 7

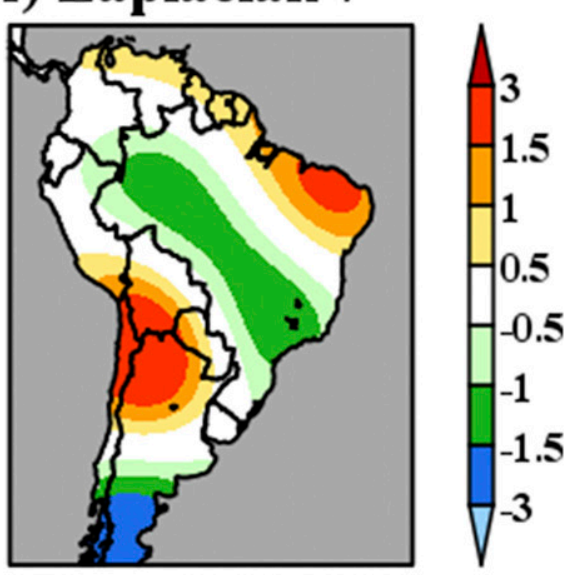

i) Laplacian 10
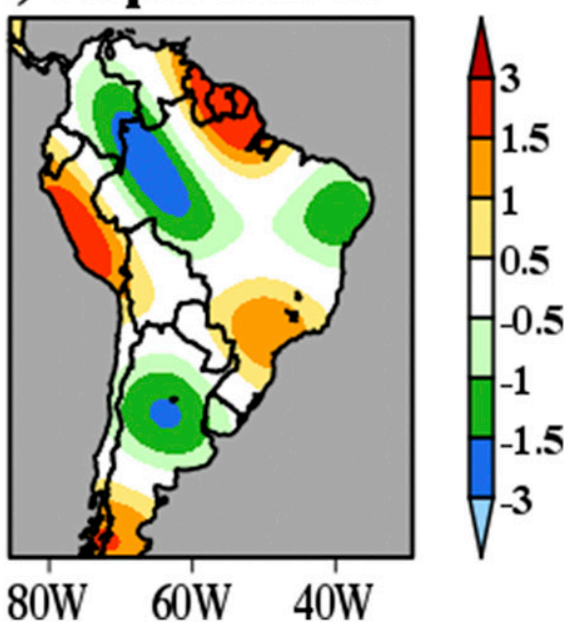

FIG. 8. Laplacian eigenfunctions 2-10 over South America.

used in the PrCA at 10 (Fig. 9a). Figure 9b presents the maximized signal-to-noise ratio for each predictable component considering the first 10 Laplacian patterns. Note that all 10 predictable components for all experiments are statistically significant at the 95\% confidence level according to a Monte Carlo (e.g., Wilks 2011) simulation. However, most of the predictability comes from the first predictable component, 

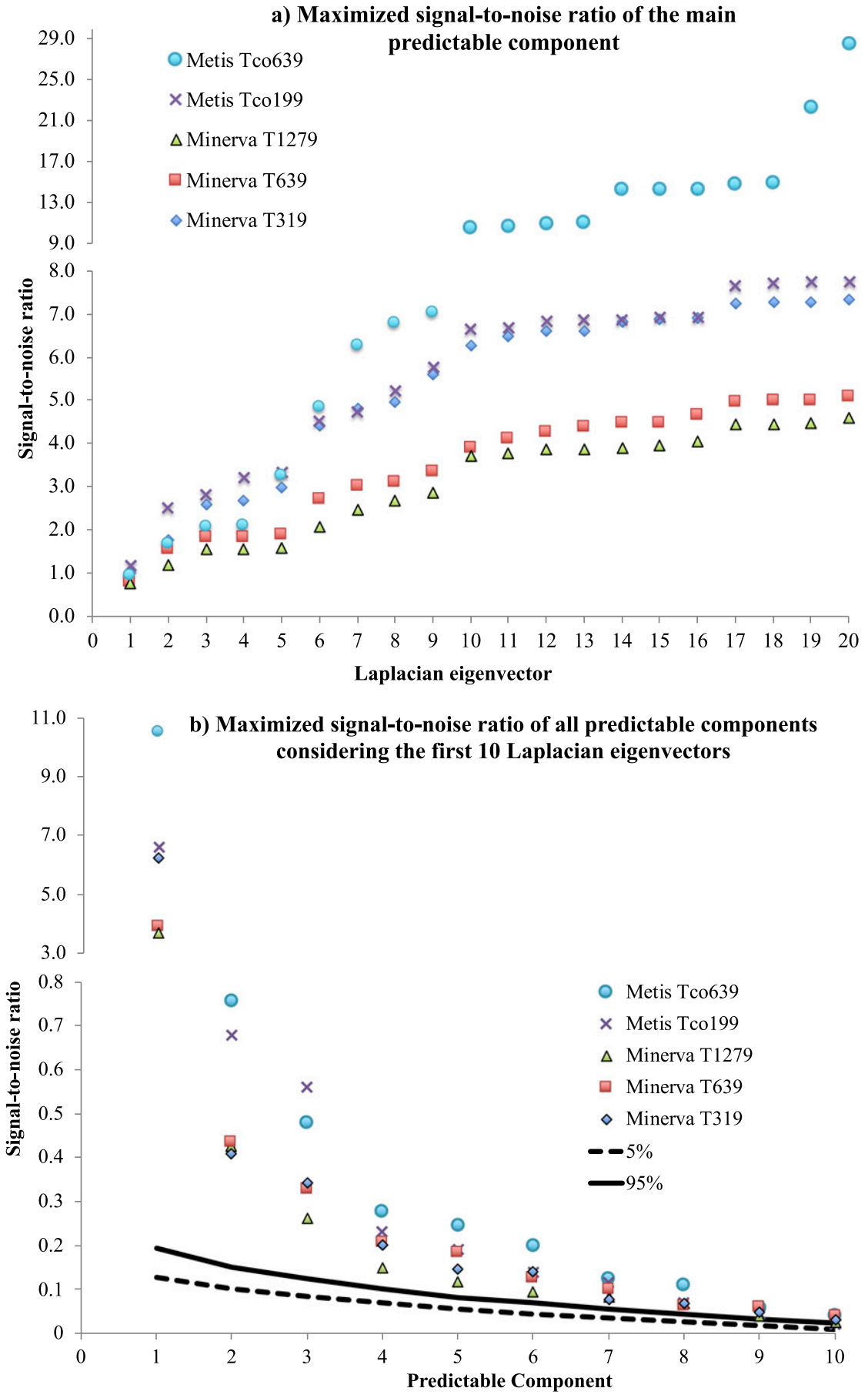

FIG. 9. (a) Maximized forecast signal-to-noise ratio of the main predictable component as a function of the number of the Laplacian eigenvectors included in the PrCA. Note the discontinuity in the $y$ axis between values 8 and 9. (b) Maximized forecast signal-to-noise ratio for each predictable component considering the first 10 Laplacian eigenvectors. Note the discontinuity in the $y$ axis between values 0.8 and 3.0. Lines show the values of the 5 th and 95th percentiles of maximized signal-to-noise ratios according to a Monte Carlo simulation, indicating that the signal-to-noise ratios are statistically significant at the $5 \%$ level. 
a) Minerva $\mathbf{T 3 1 9}$

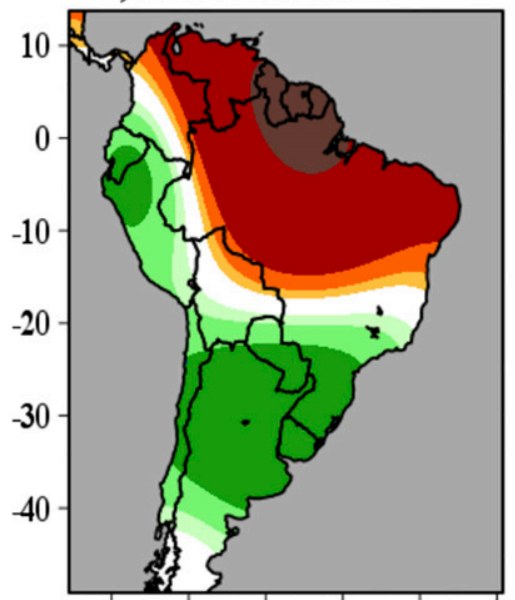

d) Metis Tco199

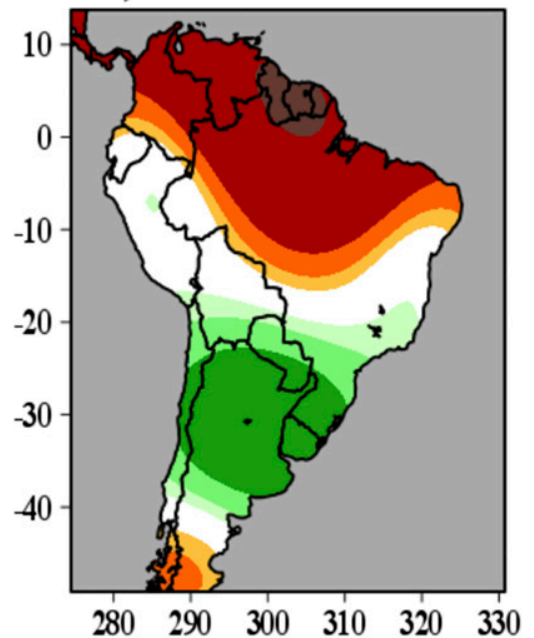

b) Minerva T639

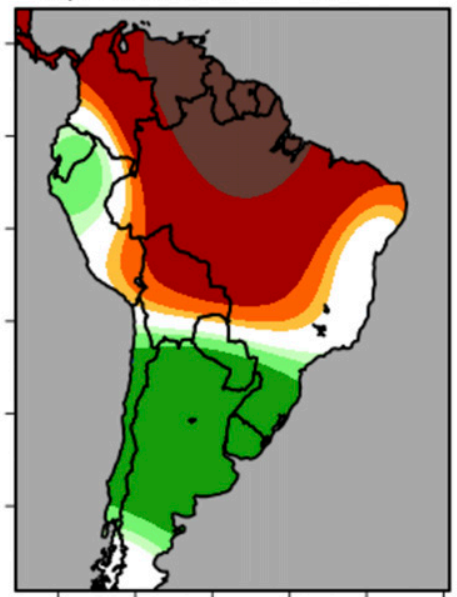

e) Metis Tco639

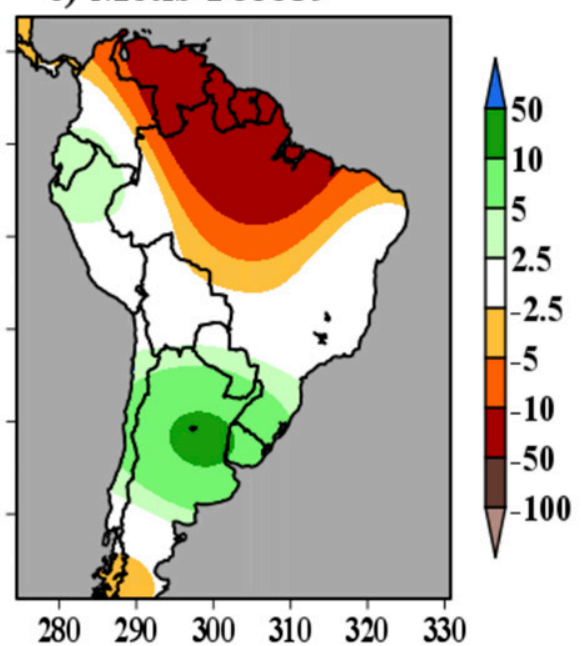

c) Minerva T1279

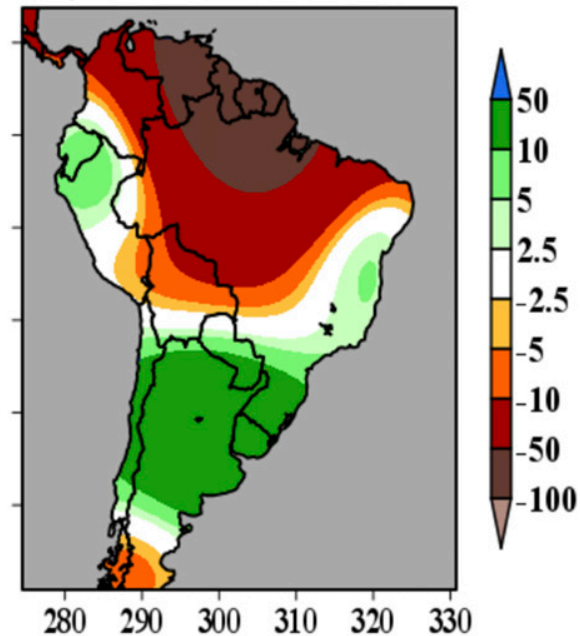

FIG. 10. Spatial pattern of the first predictable component of DJF precipitation for (a) Minerva T319, (b) Minerva T639, (c) Minerva T1279, (d) Metis Tco199, and (e) Metis Tco639. with only marginal significance for the higher-order components (Fig. 9b).

In the Minerva experiment, the maximized signal-tonoise ratio is larger when the spatial resolution of the atmospheric component is lower. In contrast, in the Metis experiment, the maximized signal-to-noise ratio is larger when the spatial resolution of the atmospheric and oceanic components is higher. In addition, Minerva T639 and Metis T1279 show very similar results, probably due to the fact they have the same spatial resolution for the atmospheric component. The same is true for Minerva T319 and Metis T199. This result suggests that there might be an optimal ratio between the spatial resolution of the atmospheric and oceanic component in the IFS_NEMO that maximizes the model's forecast signal-to-noise ratio.

The spatial pattern of the first predictable component consists of a dipole between northern and southern South America for all Minerva and Metis experiments.
This result is consistent with the findings of Jia et al. (2015). The overall amplitude of this dipole pattern is larger in the Minerva experiments than in the Metis experiments (Fig. 10). This dipole pattern suggests an influence of El Niño-Southern Oscillation (ENSO), where warm ENSO events cause dry conditions over northern South America and wet condition over southeastern South America (e.g., Ropelewski and Halpert 1987; Grimm et al. 2000).

Figure 11a shows the time series of the first predictable component for the Minerva T319 experiment as well as the time series of projected DJF precipitation anomalies and a simple ENSO index. Since it is not possible to calculate a PrCA for observations, the observed DJF precipitation anomalies were projected onto the matrix of maximized signal-to-noise ratio of each Minerva and Metis experiment. Although this is not a straightforward comparison between simulations and observations, it allows us to evaluate how well the time 
a) Time Series

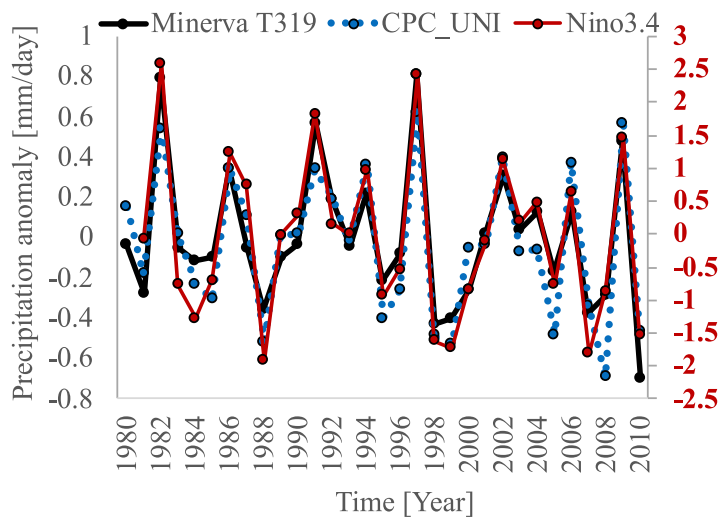

b) Correlation: Obs x PCA

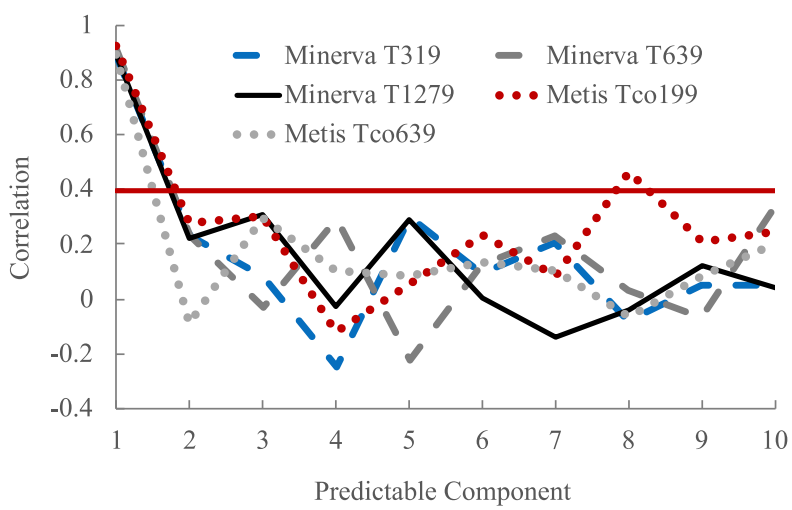

FIG. 11. (a) Time series of the main predictable component of experiment Minerva T319, projected CPC_UNI DJF precipitation anomalies, and ENSO index. (b) Correlation between the time series of each predictable component of each Minerva and Metis experiments and the time series of the projected CPC_UNI DJF precipitation anomalies.

series of the predictable component represent the time series of observed precipitation for a given predictable component spatial pattern. The ENSO index was calculated by spatially averaging sea surface temperature anomalies over the Niño-3.4 region $\left(5^{\circ} \mathrm{S}-5^{\circ} \mathrm{N}, 120^{\circ}-\right.$ $\left.170^{\circ} \mathrm{W}\right)$. We used the NOAA Optimum Interpolation $0.25^{\circ}$ Daily Sea Surface Temperature Analysis (Reynolds et al. 2007). There is a remarkable similarity among all three time series (Fig. 11a), suggesting that not only the first predictable component has skill but also that the source of the forecast skill is ENSO. This result is true for all model experiments as shown in Table 2 and it is also consistent with previous studies (Jia et al. 2015; Osman and Vera 2017). Figure 11b shows the correlation between the time series of each predictable component of each Minerva and Metis experiments and the time series of the projected observed DJF precipitation anomalies. The fact that only the first predictable component of all experiments has statistically significant correlations (Fig. 11b) indicates that only the first predictable component of all experiments has skill.

\section{Conclusions}

We evaluated the IFS_NEMO forecast skill and the predictability of summer precipitation over South America using hindcasts performed as part of the Minerva and Metis experiments. We find that the IFS NEMO has skill in predicting summer precipitation over northern South America and moderate skill over the La Plata basin, consistent with previous studies. We also find that the increase in the spatial resolution of the atmospheric component of IFS_NEMO (Minerva project) has no significant impact on the model's forecast skill of summer precipitation over South America. However, the increase in the spatial resolution of both the atmospheric and oceanic components of the IFS_NEMO (Metis runs) led to significant changes in signal and noise variance as well as in the signal-to-noise ratio. This suggests that ocean resolution may have an impact on the signal-tonoise ratio in atmospheric variables. A more thorough understanding of this behavior, including the role played by parameterizations of unresolved atmospheric and oceanic physical processes, is desirable.

Considering the predictability of large-scale patterns of summer precipitation, the most predictable pattern consists of a dipole between northern and southern South America. The source of forecast skill for this large-scale pattern is ENSO. Jia et al. (2015) found that high-resolution dynamical model simulations combined with the use of predictable component analysis led to significant skill in the seasonal prediction of precipitation. Although, our results partially support these findings, they are not supportive of increasing horizontal resolution beyond what was already achieved in the Minerva T639 with $1^{\circ}$ NEMO. Further increases in resolution will likely not lead to improved seasonal skill unless other

TABLE 2. Correlations between the time series of the first predictable component for each experiment (expt) and observations (obs).

\begin{tabular}{lccccc}
\hline \hline \multirow{2}{*}{ Obs } & \multicolumn{4}{c}{ Expt } \\
\cline { 2 - 6 } & Minerva T319 & Minerva T639 & Minerva T1279 & Metis Tco199 & Metis Tco639 \\
\hline Precipitation CPC_UNI & 0.88 & 0.91 & 0.90 & 0.92 & 0.89 \\
Niño-3.4 index & 0.94 & 0.93 & 0.92 & 0.94 & 0.95 \\
\hline
\end{tabular}


aspects of the model are developed to take advantage of the increase in resolution.

It is worth mentioning that we should not support the inference that, because the model derives its skill from ENSO, then a coupled model can be abandoned in favor of a heuristic model. The dynamical model predicts much more than a single ENSO pattern, and predicts them in a physical consistent manner. Our results (Fig. 9) shows that other predictable components are also significant, which may or may not be related to ENSO. So, a heuristic ENSO-only model may not skillfully predict as much as the dynamical model. Also, a heuristic model would require identifying the spatial response pattern associated with ENSO. How would this pattern be identified without the dynamical model? Finally, the dynamical model predicts much more than precipitation-it also predicts temperature, winds, and other variables that are linked together through specific physical mechanisms that can be diagnosed from the dynamical model. In contrast, a heuristic model may predict physically incompatible relations between variables if it is derived using only statistics and no physics.

Neither increasing spatial resolution nor the identification of large-scale patterns of predictability through the use of PrCA led to skillful forecasts over the core region of the South American monsoon. Becker et al. (2014) showed that there is potential for improving predictability of precipitation in global coupled climate models based on perfect model predictability estimates. However, our results suggest that skillful seasonal forecasts of the South American monsoon would depend on factors other than increasing spatial resolution. Future studies should investigate ways to improve the IFS NEMO forecast skill for the South Atlantic convergence zone, given that this phenomenon is likely associated with the large noise variance over central and southeastern Brazil. Seasonal prediction of precipitation remains a challenge for state-of-the-art climate models. Positive benefits of increasing model resolution might be more evident in other atmospheric fields and/or lead times.

Acknowledgments. This study was supported by the National Monsoon Mission, Ministry of Earth Sciences, government of India. Additional support comes from NSF (AGS-1338427), NOAA (NA14OAR4310160 and NA15NWS4680018), and NASA (NNX14AM19G). We thank the ECMWF METIS team (R. Buizza, D. Decremer, F. Molteni, and S. Saarinen) for their contributions to the METIS project. We also thank Drs. R. Buizza and F. Molteni for their comments that led to the improvement of this manuscript. Computing resources (ark:/85065/d7wd3xhc) were provided by the Climate Simulation Laboratory at NCAR's Computational and Information Systems Laboratory, sponsored by the National Science Foundation and other agencies.

\section{REFERENCES}

Barreiro, M., P. Chang, and R. Saravanan, 2002: Variability of the South Atlantic convergence zone simulated by an atmospheric general circulation model. J. Climate, 15, 745-763, https://doi.org/ 10.1175/1520-0442(2002)015<0745:VOTSAC $>2.0 . C O ; 2$.

,-- , and - 2005: Simulated precipitation response to SST forcing and potential predictability in the region of the South Atlantic convergence zone. Climate Dyn., 24, 105-114, https://doi.org/10.1007/s00382-004-0487-9.

Becker, E., H. van den Dool, and Q. Zhang, 2014: Predictability and forecast skill in NMME. J. Climate, 27, 5891-5906, https:// doi.org/10.1175/JCLI-D-13-00597.1.

Carvalho, L. M. V., and I. F. A. Cavalcanti, 2016: The South American Monsoon System (SAMS). The Monsoons and Climate Change, L. M. V. Carvalho and C. Jones, Eds., Springer, 121-148, https://doi.org/10.1007/978-3-319-21650-8_6.

_ C. C. Jones, and B. Liebmann, 2002: Extreme precipitation events in southeastern South America and large-scale convective patterns in the South Atlantic convergence zone. J. Climate, 15, 2377-2394, https://doi.org/10.1175/1520-0442(2002)015<2377: EPEISS $>2.0 . \mathrm{CO} ; 2$.

- - - , and - 2004: The South Atlantic convergence zone: Intensity, form, persistence, and relationships with intraseasonal to interannual activity and extreme rainfall. J. Climate, 17, 88-108, https://doi.org/10.1175/1520-0442(2004)017<0088: TSACZI $>2.0 . \mathrm{CO} ; 2$.

Cash, B. A., and Coauthors, 2017: Sampling variability and the changing ENSO-monsoon relationship. Climate Dyn., 48, 4071-4079, https://doi.org/10.1007/s00382-016-3320-3.

Chen, M., W. Shi, P. Xie, V. B. S. Silva, V. E. Kousky, R. Wayne Higgins, and J. E. Janowiak, 2008: Assessing objective techniques for gauge-based analyses of global daily precipitation. J. Geophys. Res., 113, D04110, https://doi.org/10.1029/ 2007JD009132.

Compo, G. P., and P. D. Sardeshmukh, 2004: Storm track predictability on seasonal and decadal scales. J. Climate, 17, 3701-3720, https://doi.org/10.1175/1520-0442(2004)017<3701: STPOSA $>2.0 . \mathrm{CO} ; 2$.

Dando, P., 2015: Changes to ECMWF's grids in 2016. ECMWF, 17 pp., https://www.ecmwf.int/sites/default/files/elibrary/2016/ 15398-changes-ecmwfs-grids-2016.pdf.

DelSole, T., and M. K. Tippett, 2008: Predictable components and singular vectors. J. Atmos. Sci., 65, 1666-1678, https://doi.org/ 10.1175/2007JAS2401.1.

— analysis. J. Climate, 28, 7420-7436, https://doi.org/10.1175/ JCLI-D-15-0049.1.

_ L. Trenary, M. K. Tippett, and K. Pegion, 2017: Predictability of week-3-4 average temperature and precipitation over the contiguous United States. J. Climate, 30, 3499-3512, https:// doi.org/10.1175/JCLI-D-16-0567.1.

Gates, W. L., and Coauthors, 1999: An overview of the results of the Atmospheric Model Intercomparison Project (AMIP I). Bull. Amer. Meteor. Soc., 80, 29-55, https://doi.org/10.1175/ 1520-0477(1999)080<0029:AOOTRO>2.0.CO;2.

Gonzalez, P. L. M., and C. S. Vera, 2014: Summer precipitation variability over South America on long and short intraseasonal timescales. Climate Dyn., 43, 1993-2007, https://doi.org/10.1007/ s00382-013-2023-2. 
Grimm, A. M., V. R. Barros, and M. E. Doyle, 2000: Climate variability in southern South America associated with El Niño and La Niña events. J. Climate, 13, 35-58, https://doi.org/ 10.1175/1520-0442(2000)013<0035:CVISSA $>2.0$. CO 2 .

Hirata, F. E., and A. M. Grimm, 2018: Extended-range prediction of South Atlantic convergence zone rainfall with calibrated CFSv2 reforecast. Climate Dyn., 50, 3699-3710, https://doi.org/ 10.1007/s00382-017-3836-1.

Jia, L., and Coauthors, 2015: Improved seasonal prediction of temperature and precipitation over land in a high-resolution GFDL climate model. J. Climate, 28, 2044-2062, https://doi.org/10.1175/ JCLI-D-14-00112.1.

Jones, C., and L. M. V. Carvalho, 2002: Active and break phases in the South American monsoon system. J. Climate 15, 905-914, https://doi.org/10.1175/1520-0442(2002)015<0905: AABPIT $>2.0 . \mathrm{CO} ; 2$.

Kumar, A., and M. P. Hoerling, 2000: Analysis of a conceptual model of seasonal climate variability and implications for seasonal prediction. Bull. Amer. Meteor. Soc., 81, 255-264, https://doi.org/10.1175/1520-0477(2000)081<0255: $\mathrm{AOACMO}>2.3 . \mathrm{CO} ; 2$.

Marengo, J. A., and Coauthors, 2012: Recent developments on the South American monsoon system. Int. J. Climatol., 32, 1-21, https://doi.org/10.1002/joc.2254.

Misra, V., 2004: An evaluation of the predictability of austral summer season precipitation over South America. J. Climate, 17, 1161-1175, https://doi.org/10.1175/1520-0442(2004)017<1161: $\mathrm{AEOTPO}>2.0 . \mathrm{CO} ; 2$.

Molteni, F., and Coauthors, 2011: The new ECMWF seasonal forecast system (System 4). ECMWF Tech. Memo. 656, ECMWF, 49 pp., https://www.ecmwf.int/sites/default/files/elibrary/ 2011/11209-new-ecmwf-seasonal-forecast-system-system-4.pdf.

Muza, M. N., L. M. V. Carvalho, C. Jones, and B. Liebmann, 2009: Intraseasonal and interannual variability of extreme dry and wet events over southeastern South America and the subtropical Atlantic during austral summer. J. Climate, 22, 1682-1699, https://doi.org/10.1175/2008JCLI2257.1.

Osman, M., and C. S. Vera, 2017: Climate predictability and prediction skill on seasonal time scales over South America from
CHFP models. Climate Dyn., 49, 2365-2383, https://doi.org/ 10.1007/s00382-016-3444-5.

Reynolds, R. W., T. M. Smith, C. Liu, D. B. Chelton, K. S. Casey, and M. G. Schlax, 2007: Daily high-resolution-blended analyses for sea surface temperature. J. Climate, 20, 5473-5496, https://doi.org/10.1175/2007JCLI1824.1.

Ropelewski, C. F., and M. S. Halpert, 1987: Global and regional scale precipitation patterns associated with the El Niño/Southern Oscillation. Mon. Wea. Rev., 115, 16061626, https://doi.org/10.1175/1520-0493(1987)115<1606: GARSPP $>2.0 . \mathrm{CO} ; 2$.

Sardeshmukh, P. D., G. P. Compo, and C. Penland, 2000: Changes of probability associated with El Niño. J. Climate, 13, 4268-4286, https://doi.org/10.1175/1520-0442(2000)013<4268: COPAWE $>2.0 . \mathrm{CO} ; 2$.

Shukla, J., and Coauthors, 2000: Dynamical seasonal prediction. Bull. Amer. Meteor. Soc., 81, 2593-2606, https://doi.org/ 10.1175/1520-0477(2000)081<2593:DSP > 2.3.CO;2.

Taschetto, A. S., and I. Wainer, 2008: Reproducibility of South American precipitation due to subtropical South Atlantic SSTs. J. Climate, 21, 2835-2851, https://doi.org/10.1175/ 2007JCLI1865.1.

Vera, C., and Coauthors, 2006: Toward a unified view of the American monsoon systems. J. Climate, 19, 4977-5000, https:// doi.org/10.1175/JCLI3896.1.

_, M. S. Alvarez, P. L. M. Gonzalez, B. Liebmann, and G. N. Kiladis, 2018: Seasonal cycle of precipitation variability in South America on intraseasonal timescales. Climate Dyn., https://doi.org/10.1007/s00382-017-3994-1, in press.

Wilks, D. S., 2011: Statistical Methods in the Atmospheric Sciences. 3rd ed. Academic Press, 676 pp.

Xie, P., P. A. Arkin, and J. E. Janowiak, 2007: CMAP: The CPC Merged Analysis of Precipitation. Measuring Precipitation from Space, V. Levizzani, P. Bauer, and F. J. Turk, Eds., Springer, 319-328, https://doi.org/10.1007/ 978-1-4020-5835-6_25.

Zhou, J., and K.-M. Lau, 1998: Does a monsoon climate exist over South America? J. Climate, 11, 1020-1040, https://doi.org/ 10.1175/1520-0442(1998)011<1020:DAMCEO > 2.0.CO;2. 